\title{
EFEKTIVITAS VARIASI KONSENTRASI TEPUNG TALAS (Colocasia esculenta (L.) Schott) SEBAGAI MEDIA ALTERNATIF PERTUMBUHAN JAMUR Candida albicans
}

\author{
Marchamtia Sarah Nur Awalia Fajari ${ }^{1^{*}}$, Muhammad Taufiq Qurrohman ${ }^{1}$ \\ 1Prodi Teknologi Laboratorium Medik, Sekolah Tinggi Ilmu Kesehatan Nasional, Jawa \\ Tengah, Indonesia \\ e-Mail: m.taufiqqurrohman@stikesnas.ac.id
}

\begin{abstract}
Taro flour (Colocasia esculenta (L.) Schott), high carbohydrate source has the potential to be used as an alternative media in supporting the examination of Candida albicans fungal culture. Candida albicans is one of the fungi causing candidiasis. Therefore, this study aims to see the effectiveness of the variations of taro flour concentrations as an alternative media to the growth of fungus Candida albicans. The type of the study was experimental with a post test only control group design. The subjects of the study were taro flour media with concentrations of $0,12 \%, 0,24 \%$, and $0,36 \%$ tested on fungus Candida albicans, which was inoculated by spread plate with PDA (Potato Dextrose Agar) media used as control. The data collection was performed by calculating the colony of Candida albicans, which grew in each media. The mean colony of each media on PDA, taro flour $0,12 \%, 0,24 \%, 0,36 \%$ were 15.5 colonies, 18.8 colonies, 19.5 colonies, and 20.8 colonies, respectively. The effectiveness test showed that all taro flour concentrations have a percentage more than $100 \%$. The variation of taro flour has the growth effect of fungus Candida albicans. Thus, the higher the concentration of taro flour media, the more colony the number of Candida albicans grew. The effectiveness test showed that all taro flour concentrations was classified as very effective.

Keywords : alternative media, Candida albicans, taro flour.
\end{abstract}

\begin{abstract}
Abstrak
Tepung talas (Colocasia esculenta (L.) Schott), sumber karbohidrat yang tinggi ini berpotensi dimanfaatkan dalam bentuk media alternatif untuk mendukung pada pemeriksaan kultur jamur Candida albicans. Jamur Candida albicans merupakan salah satu jamur yang menyebabkan penyakit Kandidiasis. Penelitian ini bertujuan untuk melihat efektivitas variasi konsentrasi tepung talas sebagai media alternatif terhadap pertumbuhan jamur Candida albicans. Jenis penelitian ini adalah eksperimental dengan desain post test only control group. Subjek penelitian ini adalah media tepung talas konsentrasi 0,12\%, 0,24\% dan 0,36\% yang diujikan pada jamur Candida albicans yang diinokulasikan secara Spread plate dengan media PDA (Potato Dextrose Agar) digunakan sebagai kontrol. Pengumpulan data dilakukan dengan menghitung koloni jamur Candida albicans yang tumbuh pada masing-masing media. Rerata koloni masing-masing media pada PDA, tepung talas $0,12 \%, 0,24 \%, 0,36 \%$ berturut-turut adalah 15,5 koloni, 18,8 koloni, 19,5 koloni, dan 20,83 koloni. Pada uji efektifitas semua konsentrasi tepung talas memiliki persentase lebih dari $100 \%$. Terdapat pengaruh variasi tepung talas terhadap pertumbuhan jamur Candida albicans. Semakin tinggi konsentrasi media tepung talas maka semakin banyak jumLah koloni Candida albicans yang tumbuh. Pada uji efektivitas menunjukkan bahwa pada semua konsentrasi tepung talas masuk dalam kriteria yang sangat efektif.
\end{abstract}

Kata kunci : Candida albicans, media alternatif, tepung talas. 
Media adalah campuran zat makanan yang dibutuhkan untuk pertumbuhan mikroorganisme serta berfungsi untuk isolasi, inokulasi, uji fisiologis dan biokimia mikroorganisme. Media yang baik adalah media tersebut harus memperhatikan serta mengandung semua kebutuhan untuk pertumbuhan mikroorganisme. Karbon, nitrogen, unsur non logam seperti sulfur dan fosfor, unsur logam seperti $\mathrm{Ca}, \mathrm{Zn}, \mathrm{Na}, \mathrm{Cu}, \mathrm{Mn}, \mathrm{Mg}$ dan $\mathrm{Fe}$, vitamin air dan energi merupakan beberapa nutrisi yang penting untuk pertumbuhan mikroorganisme. Salah satu contoh media untuk pertumbuhan jamur adalah Potato Dextrose Agar (PDA). PDA tergolong dalam media sintetik secara terperinci memiliki kandungan yang diketahui yaitu penambahan senyawa inorganik murni dan organik yang secara selektif menumbuhkan jamur karena kadar $\mathrm{pH}$ yang rendah $(4,5$ - 5,6) sehingga pertumbuhan bakteri dihambat (Amir dkk., 2018; Basarang dkk., 2018; Gandjar \& Sjamsuridzal, 2008; Yusmaniar dkk., 2017).

Pada studi yang dilakukan Kemal Fariz Kalista dkk. (2017) spesies Candida yang paling banyak ditemukan pada kandidiasis adalah Candida albicans diikuti oleh Candida tropicalis dan Candida parapsilosis. Kandidiasis banyak menginfeksi manusia dan diagnosis umumnya dengan pemeriksaan klinis, pemeriksaan $\mathrm{KOH}$, dan kultur. Pemeriksaan kultur jamur merupakan pemeriksaan untuk mendeteksi adanya jamur yang pada pelaksanaanya membutuhkan tidak sedikit media pertumbuhan jamur (Kalista et al., 2017; Soetojo \& Astari, 2013).

Talas dilihat dari nilai sumber karbohidrat memiliki kandungan sekitar 70-80\% yang merupakan sumber karbohidrat mudah di cerna (Minantyorini \& Hanarida, 2002). Menurut Eddy dkk. (2012) dalam Lestari dan Maharani (2017) talas memiliki kandungan gizi baik protein $(1,56 \%)$, lemak $(1,4 \%)$, karbohidrat $(41,89 \%)$, serat kasar $(0,82 \%)$, zat besi $(1,39 \mathrm{mg} / 100 \mathrm{~g})$, kalsium $(47,73$ $\mathrm{mg} / 100 \mathrm{~g})$, vitamin C $(23,82 \mathrm{mg} / 100 \mathrm{~g})$, B-karoten $(6,82 \mathrm{mg} / 100 \mathrm{~g})$, serta energi $(186,40 \mathrm{cal} / 100 \mathrm{~g})$. Menurut Sulistyowaty dkk. (2014) talas memiliki kandungan karbohidrat 23,78\%. Menurut Haris (2001) dalam Rachmawan dkk., 
(2013) Tepung talas bogor mengandung 84,00 g karbohidrat dalam $100 \mathrm{~g}$.

Kandungan yang terdapat pada talas cukup baik yaitu tinggi akan karbohidrat. Talas juga sangat mudah didapat dan ditemukan dengan harga yang lebih ekonomis dibandingkan dengan media PDA instan. Sumber daya talas yang melimpah serta apabila mengolahnya menjadi tepung talas dapat dimanfaatkan sebagai media alternatif penganti PDA (Potato Dextrose Agar) yang diharapkan setidaknya dapat memangkas penggeluaran dalam pelaksanaan praktik pemeriksaan jamur.

Berdasarkan penelitian yang dilakukan oleh Nur Indah Sari Amir dkk. (2018) mengenai tepung talas dimana tidak menyebutkan varietas umbi talas yang digunakan. Tepung talas sebagai media alternatif pertumbuhan jamur Candida albicans diperoleh hasil bahwa rata-rata jumLah koloni Candida albicans yang tumbuh pada masing-masing media yaitu media tepung talas konsentrasi $2 \%=21$ koloni, media tepung talas konsentrasi 4\% = 23,5 koloni, media tepung talas konsentrasi $6 \%=26,5$ koloni, media tepung talas konsentrasi $8 \%=29,5$ koloni dan pada kontrol media SDA = 24 koloni. Pada media tepung talas konsentrasi 4\%-8\% dinilai dapat digunakan sebagai media alternatif penganti SDA (Sabouraud Dextrose Agar) namun tidak sebaik media SDA. Oleh karena itu perlu dilakukan penelitian lanjutan untuk melihat efektivitas variasi konsentrasi serta konsentrasi efektif tepung talas sebagai media alternatif terhadap pertumbuhan jamur Candida albicans. Efektivitas dilihat dengan rumus perhitungan efektivitas sehingga konsentrasi efektif dapat diketahui. Penelitian lanjutan yang dilakukan yaitu tentang "Efektivitas Variasi Konsentrasi Tepung Talas Sebagai Media Alternatif Pertumbuhan Jamur Candida Albicans" dengan variasi konsentrasi 0,12\%; 0,24\%; dan 0,36\% kemudian membandingkannya dengan media PDA.

Bahan yang digunakan adalah kultur Candida albicans ATCC 10231, talas, aquadest, $\mathrm{NaCl} 0,9 \%$, standar $\mathrm{Mc}$ Farland $\left(\mathrm{BaCl}_{2}\right.$ dengan $\left.\mathrm{H}_{2} \mathrm{SO}_{4}\right)$, media PDA, agar, kloramfenikol, $\mathrm{KOH} \mathrm{10 \% ,} \mathrm{spirtus,} \mathrm{kapas.}$ 
Alat yang digunakan adalah pisau, talenan, nampan, oven, blender, ayakan 100 mesh, mangkok, spatel, beckerglass, erlenmeyer, petri dish, gelas ukur, tabung reaksi, rak tabung reaksi, neraca analitik, driglaski, batang pengaduk, pengukur ph, autoklaf, inkubator, pembakar spirtus, korek api, ohse, pipet, mikropipet, tip, bolpoin, latar belakang hitam, spidol.

Jenis penelitian adalah eksperimental, dengan desain penelitian Posttest only control group untuk mengetahui suatu pengaruh dari perlakuan dengan cara membandingkan kelompok eksperimen dengan kelompok kontrol. Penelitian dan Pemeriksaan dilakukan di Laboratorium Parasitologi Sekolah Tinggi Ilmu Kesehatan Nasional. Subyek penelitian adalah tepung talas sebagai media alternatif pertumbuhan jamur Candida albicans. Obyek penelitian adalah hasil pengamatan makroskopis pertumbuhan koloni jamur Candida albicans pada berbagai variasi konsentrasi tepung talas sebagai media alternatif setelah dilakukan inkubasi. Teknik pengambilan sampel yaitu menggunakan teknik Simple Random Sampling yaitu pengambilan sampel dilakukan secara acak sederhana.

Penelitian diawali dengan pembuatan tepung talas. Umbi talas dilakukan pengupasan, pencucian dengan air mengalir, pemotongan, pengeringan, penghalusan dan pengayakan sehingga didapatkan tepung talas.

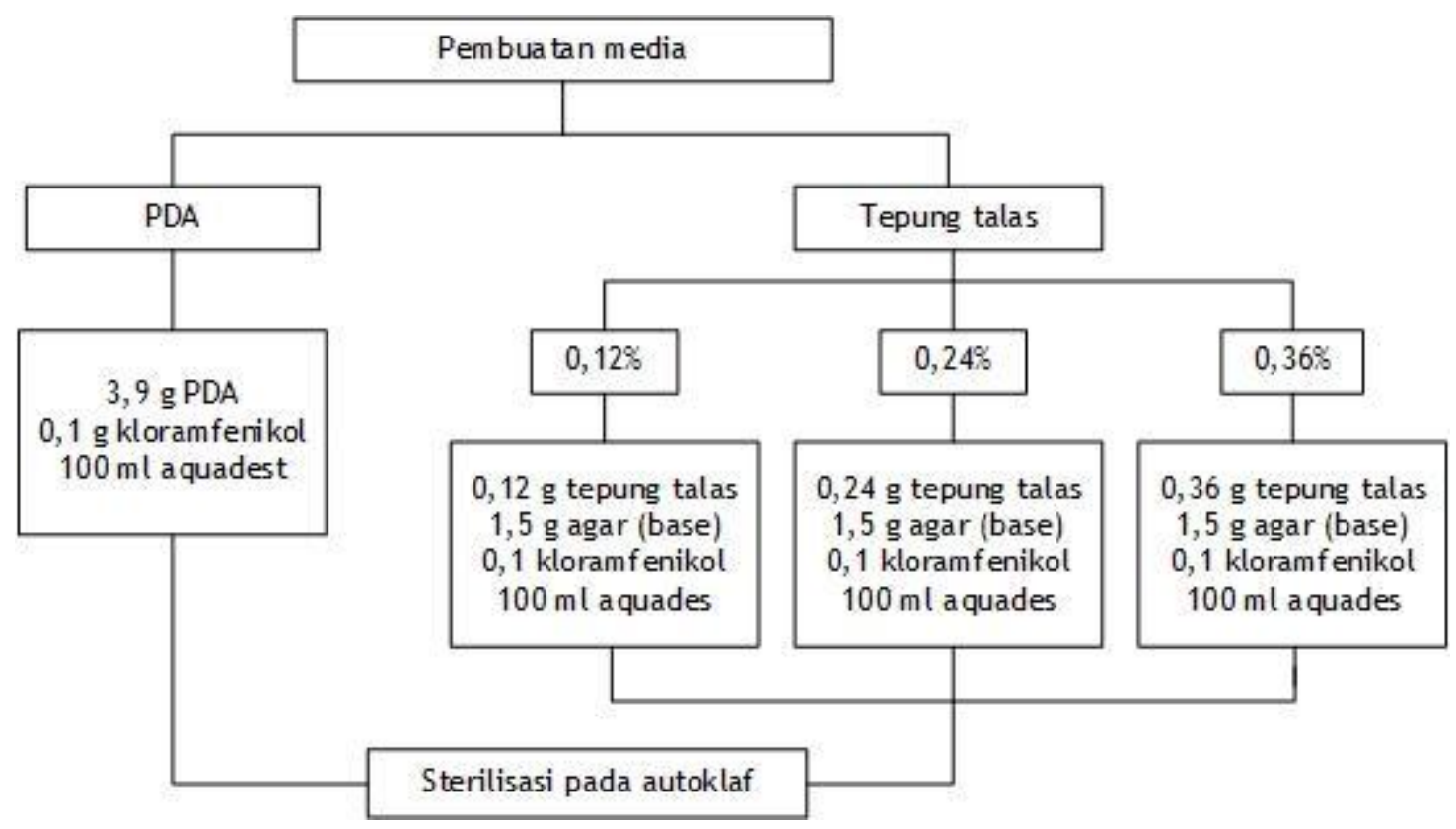


Gambar 1. Skema pembuatan media PDA dan Media tepung talas konsentrasi $0,12 \% ; 0,24 \%$ dan $0,36 \%$

Inokulasi suspensi Candida albicans yaitu sebanyak $0,1 \mathrm{~mL}$ pada masing-masing media dilakukan dengan metode Spread plate secara aseptis. Masing-masing media kemudian diinkubasi dengan suhu $37^{\circ} \mathrm{C}$ selama $3 \times 24$ jam. Pengamatan dilakukan secara makroskopis dengan menghitung koloni Candida albicans yang tumbuh pada masing-masing media. Ciri koloni jamur Candida albicans berwarna putih kekuningan, berbentuk bulat, permukaan sedikit cembung, halus, licin dan terkadang berlipat-lipat terutama pada koloni yang sudah tua (Ratnawati dkk., 2016).

Metode analisis data yang dilakukan yaitu One Way Annova. Uji ini dilakukan untuk menentukan apakah data yang diperoleh sudah terdistribusi normal dan homogenitas sampel pada tingkat kepercayaan 95\% atau $a=0,05$ dengan bantuan program SPSS.

Tepung talas sebagai media alternatif pertumbuhan jamur Candida albicans dapat diketahui efektivitas dengan menggunakan rumus sebagai berikut :

$$
\text { Efektivitas }=\frac{\text { Rerata } \text { jumlah } \text { koloni tiap }- \text { tiap konsentrasi }}{\text { Rerata jumlah koloni kontrol }} \times 100 \%
$$

(Sumber : Depdagri, Kepmendagri No. 900. 327 Th 1996 dalam Nuryati dan Huwaina, 2015)

Perhitungan dilakukan pada rerata jumLah pertumbuhan koloni jamur Candida albicans pada masing-masing konsentrasi media tepung talas. Persentase efektivitas diketahui dengan pembagian antara rerata jumLah koloni jamur pada media tepung talas dengan rerata jumLah koloni jamur pada media PDA kemudian dikalikan 100\%. Hasil perhitungan yang diperoleh kemudian dicocokkan pada tabel 1 untuk mengetahui kriteria efektivitas. 
Tabel 1. Kriteria Efektivitas

\begin{tabular}{cc}
\hline Persentase & Kriteria \\
\hline$>100 \%$ & Sangat Efektif \\
\hline $90-100 \%$ & Efektif \\
\hline $80-90 \%$ & Cukup Efektif \\
\hline $60-80 \%$ & Kurang Efektif \\
\hline$<60 \%$ & Tidak Efektif \\
\hline
\end{tabular}

Sumber: Depdagri, Kepmendagri No. 900. 327 Th 1996 dalam Nuryati \& Huwaina, 2015

Penelitian ini dilakukan pengamatan dengan menghitung pertumbuhan koloni jamur Candida albicans ATCC 10231 dengan perlakuan inokulasi pada media tepung talas konsentrasi $0,12 \%, 0,24 \%$ dan $0,36 \%$.

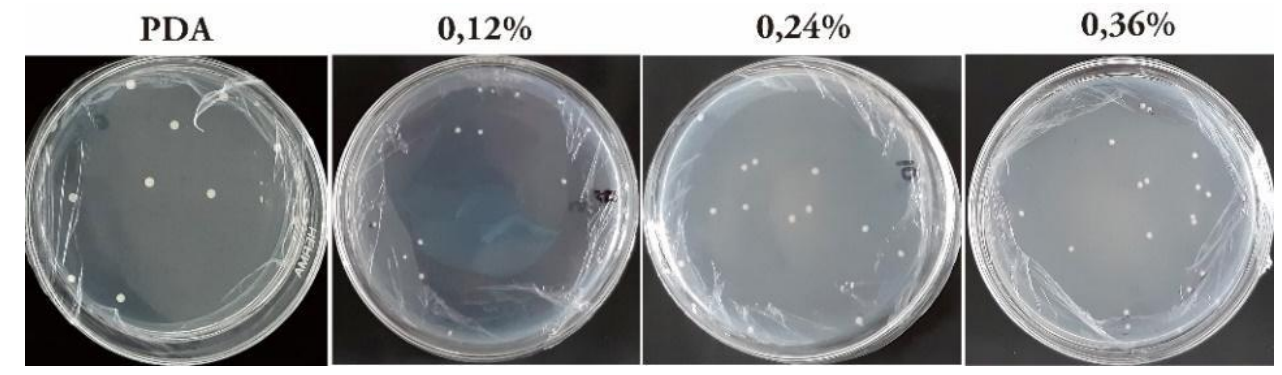

Gambar 2. Makroskopis koloni jamur Candida albicans pada media PDA dan Media alternatif tepung talas konsentrasi $0,12 \%, 0,24 \%$ dan $0,36 \%$. Candida albicans diinokulasikan pada media PDA sebagai pembanding.

Replikasi dilakukan sebanyak enam kali pada masing-masing kelompok media dan pengamatan pertumbuhan koloni jamur Candida albicans yang tumbuh dilakukan pada hari ketiga. Tampak perbedaan diameter ukuran koloni Candida albicans pada media PDA dengan media tepung talas yaitu koloni pada media PDA memiliki diameter yang lebih besar dibandingkan dengan ketiga konsentrasi media tepung talas (Gambar 2). Data perhitungan jumlah koloni jamur Candida albicans yang tumbuh pada masing-masing media didapatkan hasil seperti pada Tabel 2 sebagai berikut : 
Tabel 2. Hasil pertumbuhan koloni jamur Candida albicans setelah inkubasi 3 × 24 jam pada masing-masing media

\begin{tabular}{cccccccccc}
\hline \multirow{2}{*}{ Media } & \multicolumn{1}{c}{ Replikasi } & \multicolumn{1}{c}{ JumLa } & \multirow{2}{*}{ Rata-rata } \\
\cline { 2 - 7 } & $\mathbf{1}$ & $\mathbf{2}$ & $\mathbf{3}$ & $\mathbf{4}$ & $\mathbf{5}$ & $\mathbf{6}$ & $\mathbf{h}$ & \\
\hline PDA & 15 & 17 & 17 & 18 & 13 & 13 & 93 & 15,5 \\
Tepung talas konsentrasi $0,12 \%$ & 28 & 16 & 11 & 18 & 20 & 20 & 113 & 18,8 \\
Tepung talas konsentrasi $0,24 \%$ & 19 & 24 & 16 & 20 & 16 & 22 & 117 & 19,5 \\
Tepung talas konsentrasi $0,36 \%$ & 20 & 23 & 22 & 21 & 14 & 25 & 125 & 20,8 \\
\hline
\end{tabular}

Perhitungan jumlah koloni jamur Candida albicans yang tumbuh pada masing-masing media kemudian dirata-rata didapatkan hasil seperti pada Gambar 3 sebagai berikut:

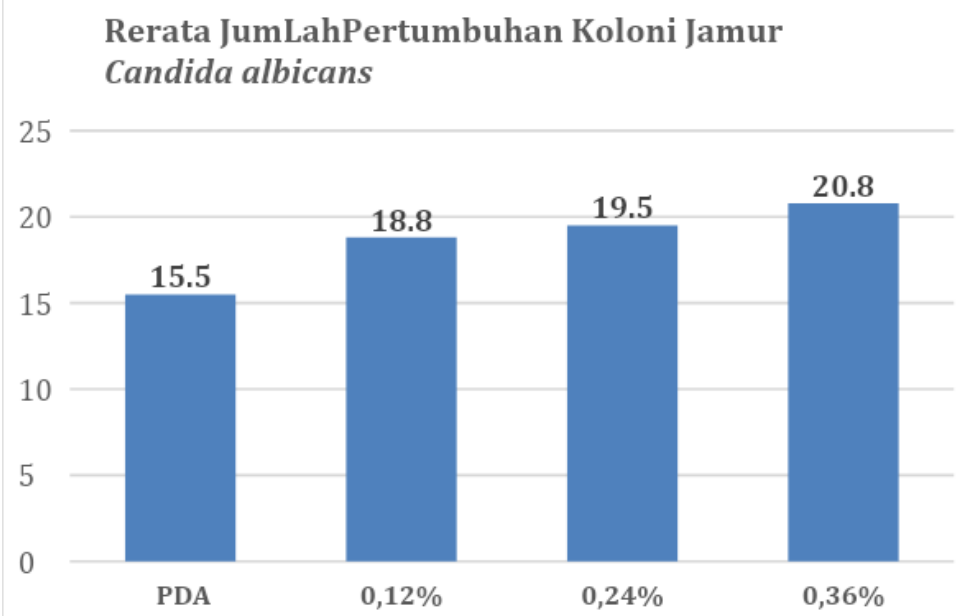

Gambar 3. Rerata pertumbuhan koloni jamur Candida albicans setelah inkubasi $3 \times 24$ jam pada masing-masing media.

Hasil Analisa data statistik untuk uji normalitas menggunakan Saphiro Wilk nilai signifikasi PDA $=0,215$, Tepung talas $0,12 \%=0,770$, tepung talas $0,24 \%=0,571$, dan tepung talas $0,36 \%=0,339$. Uji ini digunakan untuk menguji kenormalan distribusi varians. Dari hasil diketahui keseluruhan varian sigma $>0,05$ sehingga $\mathrm{H}_{0}$ diterima, artinya varian dalam kelompok terdistribusi 
secara normal. Pada uji homogenitas didapatkan nilai signifikasi $=0,556$ yaitu $>0,05$ sehingga variasi dalam kelompok homogen. Data yang normal dan homogen maka dilanjutkan uji ANOVA, nilai signifikasi didapatkan 0,140 dimana sigma > 0,05 artinya antara keempat kelompok tersebut terdapat perbedaan rata-rata yang signifikan antara jumLah koloni pertumbuhan jamur Candida albicans pada media PDA dan variasi media tepung talas 0,12\%, 0,24\% dan $0,36 \%$.

Rerata jumlah pertumbuhan koloni jamur Candida albicans pada setiap variasi konsentrasi media tepung talas setelah dilakukan perhitungan uji efektivitas didapatkan hasil seperti pada Tabel 3 sebagai berikut :

Tabel 3. Efektivitas variasi konsentrasi tepung talas sebagai media alternatif pertumbuhan jamur Candida albicans

\begin{tabular}{ccl}
\hline Media & Persentase & Kriteria \\
\hline Tepung talas konsentrasi 0,12\% & $121,50 \%$ & Sangat Efektif \\
\hline Tepung talas konsentrasi 0,24\% & $125,81 \%$ & Sangat Efektif \\
\hline Tepung talas konsentrasi $0,36 \%$ & $134,41 \%$ & Sangat Efektif \\
\hline
\end{tabular}

Ketiga variasi konsentrasi media tepung talas setelah dilakukan perhitungan didapatkan hasil yang lebih dari 100\%. Dari hasil persentase ketiga varisi konsentrasi media tepung talas dapat dikatakan masuk dalam kategori sangat efektif.

Pertumbuhan dan perkembangan jamur membutuhkan faktor lingkungan dan nutrien yang sesuai. Nutrien dapat berupa senyawa ataupun unsur kimia yang berasal dari lingkungan yang digunakan sel sebagai elemen kimia pembentuk sel. Secara universal nutrien yang dibutuhkan dalam bentuk karbon, nitrogen, sulfur, fosfor, kalsium, kalium, magnesium, natrium, nutrient mikro (besi, mangan, zink, kobalt) serta vitamin. Kandungan berbagai macam komponen nutrien salah satunya terdapat dalam tepung talas. Tepung talas memiliki kandungan nutrisi bagi kesinambungan hidup jamur yang dapat 
menyebabkan jamur Candida albicans tumbuh pada media ini (Naim dkk., 2020; Minantyorini dan Hanarida, 2002; Eddy dkk., 2012 dalam Lestari dan Maharani, 2017; Sulistyowaty dkk., 2014; Haris, 2001 dalam Rachmawan dkk., 2013).

Tepung talas pada penelitian ini digunakan untuk media alternatif sebagai nutrien utama bagi jamur Candida albicans. Nutrien-nutrien dapat dimanfaatkan apabila jamur mengeksresikan enzim-enzim ekstraselular yang dapat mengurai senyawa-senyawa kompleks menjadi yang lebih sederhana. Tepung talas memiliki karbohidrat yang tinggi maka jamur Candida albicans mengeksresikan enzim a-amilase untuk mengubah karbohidrat kompleks menjadi senyawa sederhana kemudian dapat diserap oleh jamur untuk pertumbuhannya. Pada penelitian ini antara media PDA (Potato Dextrose Agar) dengan media tepung talas terdapat perbedaan ukuran diameter koloni. Koloni terbentuk dari kumpulan miselium yang banyak. Untuk menjadi suatu koloni dalam pertumbuhan jamur disebabkan oleh pembagian sel-sel jamur menjadi sejumLah anak sel. Pertambahan populasi yang sebenarnya merupakan proses reproduksi sehingga membentuk koloni. Media tepung talas memberikan pertumbuhan koloni jamur Candida albicans yang lebih kecil dikarenakan mengandung nutrisi kompleks sehingga membutuhkan waktu lebih untuk jamur menguraikan dalam bentuk yang lebih sederhana agar dapat diserap dan dimanfaatkan pada pertumbuhan jamur. Pada media PDA tampak pertumbuhan koloni yang dapat dikatakan ideal dengan diameter koloni yang lebih besar dikarenakan PDA memiliki formulasi yang sederhana dan merupakan media terbaik karena kemampuannya mendukung pertumbuhan berbagai jenis jamur (Gandjar dan Sjamsuridzal, 2008; Rohmi dkk., 2019).

Pada setiap media konsentrasi tepung talas memiliki selisih rerata 1 koloni, yaitu pada media tepung talas $0,12 \%$ terdapat rerata 18,8 koloni, media tepung talas $0,24 \%$ terdapat rerata 19,5 koloni dan pada media tepung talas 0,36\% terdapat rerata 20,8 koloni jamur Candida albicans yang tumbuh (Gambar 3). Hasil Analisa statistik menggunakan uji One Way Anova dapat disimpulkan bahwa jumLah rata-rata pertumbuhan koloni pada media PDA dengan media tepung talas tersebut terdapat perbedaan yang signifikan. 
Dengan demikian

dapat disimpulkan bahwa media tepung talas dapat digunakan sebagai penganti media PDA.

Pada hasil penelitian ini menunjukkan bahwa semakin tinggi konsentrasi media tepung talas maka semakin banyak jumLah koloni jamur Candida albicans yang tumbuh dibandingkan dengan PDA sebagai media kontrol. Hal ini sejalan dengan penelitian yang dilakukan oleh Anik Nuryati dan Ahsanul Dian Huwaina (2015) tentang efektivitas berbagai konsentrasi kacang kedelai (Glycine max (L.) Meriil) sebagai media alternatif terhadap pertumbuhan jamur Candida albicans bahwa semakin tinggi konsentrasi kacang kedelai maka rata-rata jumLah koloni jamur yang tumbuh semakin banyak dibandingkan dengan media SDA (Sabouraud Dextrose Agar) sebagai kontrol. Nurlina Naim dkk. (2020) dalam penelitiannya tentang efektivitas berbagai variasi konsentrasi bekatul terhadap pertumbuhan Candida albicans menyimpulkan semakin tinggi konsentrasi bekatul ditemukan semakin banyak terbentuk koloni jamur Candida albicans. Penelitian sebelumnya tentang tepung talas sebagai media alternatif terhadap pertumbuhan Candida albicans yang dilakukan oleh Nur Indah Sari Amir dkk. (2018) juga menunjukkan peningkatan pertumbuhan koloni jamur Candida albicans pada konsentrasi $2 \%$, 4\%, 6\% dan 8\% dengan SDA sebagai media kontrol namun ukuran koloni pada media kontrol lebih besar dibandingkan ukuran koloni media tepung talas sehingga apabila dilihat dari jumLah pertumbuhan koloni jamur Candida albicans yang mendekati kontrol disimpulkan media tepung talas pada konsentrasi 4\%-8\% dapat digunakan untuk media alternatif pengganti SDA namun tidak sebaik SDA.

Efektivitas masing-masing variasi konsentrasi media tepung talas diketahui dengan melakukan perhitungan menggunakan rumus efektivitas. Hasil efektivitas menunjukkan bahwa media tepung talas 0,12\% memiliki persentase $121,50 \%$; media tepung talas 0,24\% memiliki persentase $125,81 \%$; dan media tepung talas $0,26 \%$ memiliki persentase $134,41 \%$ (Tabel 2). Ketiga 
variasi konsentrasi media tepung talas memiliki persentase $>100 \%$ maka termasuk dalam kriteria sangat efektif.

Kriteria sangat efektif ini terjadi karena rerata jumLah koloni jamur Candida albicans yang tumbuh pada media tepung talas konsentrasi $0,12 \%$; 0,24\%; dan 0,36\% lebih banyak dibandingkan dengan rerata jumLah koloni yang tumbuh pada media PDA sebagai kontrol yang hanya 15,5 rerata koloni jamur Candida albicans. PDA sebagai media kontrol dilihat dari komposisinya terdiri atas kentang dan dextrose sebagai sumber nutrisi sedangkan media tepung talas menggunakan tepung talas yang kaya akan karbohidrat sebagai sumber nutrisinya memberikan hasil rerata koloni jamur Candida albicans yang tumbuh cukup berbeda lebih banyak pada media tepung talas. Hal ini menegaskan bahwa kandungan nutrisi kompleks pada tepung talas dimanfaatkan oleh jamur Candida albicans untuk pertumbuhan dan perkembangannya.

Berdasarkan penelitian ini, disarankan untuk penelitian selanjutnya dapat melakukan optimasi konsentrasi media tepung talas dengan menggunakan metode lain, spesies jamur yang berbeda atau dengan bahan alam lain yang potensial. Keterbatasan pada penelitian ini adalah tidak dilakukan analisis terhadap kandungan nutrien dari tepung talas yang digunakan.

Variasi konsentrasi media tepung talas memiliki pengaruh terhadap pertumbuhan jamur Candida albicans yaitu semakin tinggi konsentrasi media tepung talas yang digunakan semakin banyak koloni jamur Candida albicans yang tumbuh. Rerata jumLah koloni jamur Candida albicans yang tumbuh pada media tepung talas konsentrasi $0,12 \%, 0,24 \%$ dan $0,36 \%$ berturut-turut adalah 18,83 koloni; 19,5 koloni; dan 20,83 koloni. Uji efektivitas media tepung talas konsentrasi 0,12\%; 0,24\%; dan 0,36\% memberikan hasil berturut turut adalah 
$121,50 \% ; 125,81 \%$; dan 134,41\%. Ketiga variasi konsentrasi tepung talas dapat disimpulkan termasuk pada kriteria yang sangat efektif.

Tidak memiliki konflik kepentingan dalam penelitian ini.

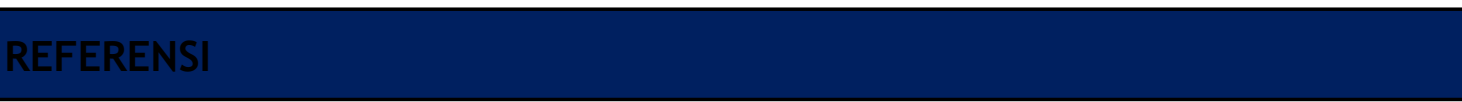

Amir, Sari, N. I., Darmawati, \& Dewi, S. S. (2018). Tepung Talas sebagai Media Alternatif Pertumbuhan Candida albicans dan Aspergillus sp. Prosiding Seminar Nasional Mahasiswa Unimus, 1, 78-85.

Basarang, M., Naim, N., \& Rahmawati. (2018). Perbandingan Pertumbuhan Jamur Pada Media. Prosiding Seminar Hasil Penelitian, 20(5), 121-125.

Gandjar, I., \& Sjamsuridzal, W. (2008). Mikrobiologi Terapan. Jakarta: Erlangga.

Kalista, K. F., Chen, L. K., Wahyuningsih, R., \& Rumende, C. M. (2017). Karakteristik Klinis dan Prevalensi Pasien Kandidiasis Invasif di Rumah Sakit Cipto Mangunkusumo. Jurnal Penyakit Dalam Indonesia, 4(2), 56.

Lestari, A. D. \& Maharani, S. (2017). Pengaruh Substitusi Tepung Talas Belitung (Xantosoma Sagittifolium) Terhadap Karakteristik Fisika, Kimia Dan Tingkat Kesukaan Konsumen Pada Roti Tawar. EDUFORTECH. Vol. 2, No. 2.

Minantyorini, \& Hanarida, S. I. (2002). Panduan Karakterisasi dan Evaluasi Plasma Nutfah Talas. Bogor : Departemen Pertanian Badan Penelitian dan Pengembangan Pertanian Komisi Nasional Plasma Nutfah.

Naim, N., Arifuddin, M., Hurustiaty.,\& Hasan, Z. A. (2020). Efektifitas Berbagai Variasi Konsentrasi Bekatul Terhadap Pertumbuhan Candida albicans. Jurnal Media Analis Kesehatan, 11(1), 47-55.

Nuryati, A., \& Huwaina, A. D. (2015). Efektivitas Berbagai Konsentrasi Kacang Kedelai ( Glycine max ( L .) Merill ) Sebagai Media Alternatif Terhadap Pertumbuhan Jamur Candida albicans. Jurnal Teknologi Laboratorium, 5(1), 5-8.

Rachmawan, O., Taofik, A., \& Suwarno, N. (2013). Penggunaan Tepung Talas Bogor (Colocasia esculenta L. Schott) terhadap Sifat Fisik dan Akseptabilitas Nagget Ayam Petelur Afkir. Jurnal ISTEK, 7(2), 152-162.

Ratnawati, Kardhinata, E. H., \& Sartini. (2016). BioLink Pusat Haji Adam Malik Medan Identification and Determination Fungi which Infected of Skin Toddler Patient in General Hospital Center Haji Adam Malik Medan. 2(2), 90-99. 
Rohmi, R., Fikri, Z., \& Pujasari, N. K. R. (2019). Ubi Jalar Putih (Ipomoea Batatas L.) Media Alternatif Pertumbuhan Aspergillus Niger. Jurnal Kesehatan Prima, 13(2), 143.

Soetojo, S., \& Astari, L. (2013). Profil Pasien Baru Infeksi Kandida pada Kulit dan Kuku (Profile of New Patients with Candida Infection in Skin and Nail). 28, 34-41.

Sulistyowaty, P. V., Kendarini, N., \& Respatijarti. (2013). Observasi Keberadaan Tanaman Talas-Talasan Genus Colocasia dan Xanthosoma Di Kec. Kedungkandang Kota Malang Dan Xanthosoma In Kedungkandang Subdistrict And Ampel Gading. Jurnal Produksi Tanaman, 2(2), 86-93.

Yusmaniar, Wardiyah, MSi, A. N. (2017). Mikrobiologi dan Parasitologi. Jakarta: Badan PPSDM Kementrian Kesehatan Republik Indonesia. 